\title{
Prostatic Fluid
}

National Cancer Institute

\section{Source}

National Cancer Institute. Prostatic Fluid. NCI Thesaurus. Code C100896.

A slightly alkaline fluid produced by the prostate gland. It contributes $20-30 \%$ of the total volume of seminal fluid. 